\title{
Cooperación política transnacional para la interoperabilidad de los negocios electrónicos
}

\author{
María de Lourdes Marquina Sánchez ${ }^{1 *}$ \\ Universidad Autónoma de la Ciudad de México \\ Alejandro Arnulfo Ruiz León** \\ Universidad Nacional Autónoma de México
}

\section{Resumen}

El actual paradigma tecno-económico de las tecnologías de información y comunicación es reflejo de las transformaciones en la estructura económica y política de la sociedad mundial. El desarrollo de Internet como un espacio económico que rebasa las fronteras geo-políticas de los mercados nacionales tradicionales ha propiciado la cooperación entre organizaciones internacionales de base gubernamental y asociaciones empresariales trasnacionales que tienen por interés asegurar la interoperabilidad de los negocios electrónicos, mediante el desarrollo de un lenguaje universal (Universal Business Language, UBL).

Palabras clave: interoperabilidad - esferas de autoridad - UBL - negocios electrónicos - tecnologías globales - redes políticas.

\begin{abstract}
The present techno-economic paradigm of information and communication technologies is a reflection of the transformations in the political and economical structures of world society. The development of Internet as an economic place which goes beyond geo-political frontiers of traditional national markets has favored the cooperation between international governmental organizations and transnational business associations whose interest is to guarantee the interoperability of electronic business through the development of a universal language (Universal Business Language, UBL).
\end{abstract}

Key words: interoperability - authority spheres- UBL- electronic business- global technologies- policy networks.

En este trabajo partimos de la hipótesis de que el cambio de paradigma tecnoeconómico suscita modificaciones en la estructura política de la sociedad mundial ya que las empresas trasnacionales ejercen en coordinación con los organismos internacionales gubernamentales, un rol de autoridad que les permite influir y participar activamente en la toma de decisiones relacionadas con el comercio en Internet, como es el caso de la creación de un lenguaje universal para los negocios electrónicos.

\footnotetext{
${ }^{1}$ Enviar correspondencia a: María de Lourdes Marquina Sánchez (marquinalulu@gmail.com)

* Profesora e investigadora en la Academia de Ciencia Política y Administración Urbana, Universidad Autónoma de la Ciudad de México (UACM), México.

** Laboratorio de Redes, Departamento de Modelación Matemática de Sistemas Sociales, Instituto de Investigaciones en Matemáticas Aplicadas y en Sistemas, Universidad Nacional Autónoma de México.
} 
REDES- Revista hispana para el análisis de redes sociales

Vol.17,\#5, Diciembre 2009

http: // revista-redes.rediris.es

Para ello, nos hemos propuesto reflexionar sobre las nuevas formas de organización política que emergen en el cambio de paradigma tecno-económico provocado por los desarrollos tecnológicos de la micro-electrónica, la informática y las telecomunicaciones, resaltando la utilidad metodológica del análisis de redes sociales (ARS) para observar las relaciones de poder en la sociedad mundial contemporánea. Para ello, nos hemos apoyado en algunas de las categorías que utiliza el ARS, a fin de identificar y conocer el tipo de relaciones que construyen los actores internacionales involucrados en la creación del lenguaje universal para los negocios electrónicos.

Con este fin hemos dividido el presente artículo en tres apartados. En el primero, exponemos el concepto de paradigma tecno-económico propuesto por Carlota Pérez y Christopher Freeman (Pérez, 2003), a fin de comprender las nuevas estructuras políticas que emergen en la sociedad internacional debido al cambio tecnológico provocado por el desarrollo de las tecnologías de información y comunicación. En el segundo apartado, exponemos la problemática mundial que suscita la importancia de desarrollar un lenguaje universal para los negocios electrónicos y su vinculación con el proceso de globalización de la economía mundial. Finalmente, en el tercer apartado, analizamos la red de cooperación política que emerge para resolver esta problemática mundial. Para ello, identificamos a los actores internacionales que están involucrados en la creación de dicho lenguaje y analizamos los vínculos de cooperación que establecen entre ellos y que nos reflejan el cambio socioinstitucional del nuevo paradigma tecno-económico basado en la formación de redes políticas entre actores internacionales y actores globales, algunos de ellos de carácter privado.

\section{El nuevo paradigma tecno-económico de las tecnologías de información y comunicación}

El capitalismo global implica un cambio histórico que emerge con el nuevo paradigma tecno-económico basado en las tecnologías de información y comunicación $(\mathrm{TICS})^{2}$, el proceso de globalización y la descentralización del poder político. Vivimos una revolución tecnológica basada en las tecnologías de información y comunicación que ha provocado fuertes cambios en las estructuras

\footnotetext{
2 Las tecnologías de información y comunicación se refieren a los medios colectivos para reunir, almacenar, transmitir, procesar y recuperar electrónicamente palabras, números, imágenes y sonidos, así como a los medios electrónicos para controlar máquinas de toda especie, desde los aparatos de uso cotidiano hasta las vastas fábricas automatizadas (Gerstein, 1988: 5).
} 
REDES- Revista hispana para el análisis de redes sociales

Vol.17,\#5, Diciembre 2009

http: // revista-redes.rediris.es

económicas y político-culturales de todos los países del mundo. Estos cambios nos llevan a pensar que hay rasgos distintivos que hacen de estos tiempos una época especial, como pudo serlo también la revolución industrial de los siglos XVII y XVIII.

La revolución industrial, al igual que la revolución de las TICS, son provocadas por el desarrollo de conocimientos científicos previos que se han materializado en importantes avances tecnológicos. Recordemos que las aplicaciones de la máquina de vapor en las empresas de aquélla época provocaron profundos cambios en la organización de la producción, la distribución, el transporte y el trabajo. Los talleres artesanales se convirtieron en grandes empresas que comenzaron a operar por todo el mundo, gracias a los desarrollos tecnológicos que permitieron el mejoramiento de los sistemas de transporte y distribución de mercancías a través del ferrocarril.

En la actual revolución provocada por las TICs observamos que los desarrollos tecnológicos de los sectores de la micro-electrónica, la informática y las telecomunicaciones han transformado las formas de organización de la producción, la comercialización y la distribución de las mercancías, situación que conlleva a la generación de nuevas formas de cooperación política entre los actores sociales involucrados en la toma de decisiones relacionadas con dichos cambios. Los cambios tecnológicos no sólo implican la generación de innovaciones tecnológicas que afectan la estructura económica de las sociedades sino también conducen a la modificación de las estructuras políticas y socio-institucionales, lo cual nos refleja la emergencia de un nuevo paradigma tecno-económico, es decir, de formas distintas de hacer las cosas, de nuevos patrones para organizar las actividades económicas y productivas que repercuten en la esfera socio-política de las civilizaciones en una etapa histórica específica ${ }^{3}$.

Un paradigma tecno-económico, es un conjunto de sistemas tecnológicos nuevos que crecen y se difunden con formas específicas de interrelación en la esfera productiva. Un paradigma tecno-económico es pues un grupo o sistema de innovaciones técnicas y organizativas interrelacionadas, cuyas ventajas se van a encontrar no sólo en una nueva gama de productos sino en la dinámica de la

\footnotetext{
${ }^{3}$ La noción de paradigma tecno-económico, elaborada por los economistas Carlota Pérez y Christopher Freeman, se fundamenta en el estudio filosófico de Thomas Kuhn sobre las revoluciones científicas así como en las aportaciones de Joseph Shumpeter sobre el cambio tecnológico.
} 
REDES- Revista hispana para el análisis de redes sociales

Vol.17,\#5, Diciembre 2009

http: // revista-redes.rediris.es

estructura económica. En cada nuevo paradigma, dice Freeman (citado en Pérez, 2002), un insumo particular o conjunto de insumos puede describirse como el factor clave de ese paradigma, caracterizado por la caída de sus costos relativos y por su disponibilidad universal. El cambio de paradigma actual puede verse como el paso de una estructura productiva basada fundamentalmente en insumos baratos de energía, a otra estructura económica basada en insumos baratos de información, derivados de los avances en la microelectrónica, la informática y las telecomunicaciones. Carlota Pérez enriquece la noción de paradigma tecnoeconómico de Freeman apuntando que las innovaciones producen efectos múltiples y variados que van más allá de los cambios en la organización económica y empresarial (gerencial), ya que las innovaciones tecnológicas repercuten no sólo en la estructura de los mercados (micro y macro) sino también en las estructuras socio-institucionales, es decir, políticas y culturales, ya que para impulsar los cambios económicos derivados del surgimiento de las nuevas tecnologías, se necesitan hacer cambios en la esfera socio-institucional que respalden y promuevan las nuevas formas de organización de la producción, del trabajo y del modelo de acumulación para el crecimiento económico (Pérez, 2003).

Apoyándonos en las investigaciones de Carlota Pérez quien afirma que cada paradigma tecno-económico se construye y difunde en tres momentos interrelacionados, aunque en contextos tecno-históricos distintos, proponemos caracterizar el nuevo paradigma tecno-económico de las TICS, a partir de: i) el cambio tecnológico ocurrido por el desarrollo de Internet; ii) el cambio económico suscitado por el fenómeno de la globalización, el cual está técnicamente sustentado en el desarrollo de las TICS y, iii) el cambio socio-institucional y político necesario para resolver las problemáticas globales que provoca este nuevo paradigma tecnoeconómico que afecta a la sociedad mundial en su conjunto.

En el siguiente diagrama podemos apreciar la interrelación que existe entre las innovaciones tecnológicas de los sectores de la microelectrónica, la informática y las telecomunicaciones y los cambios económicos y socio-políticos que éstas generan, generando así el nuevo paradigma tecno-económico basado en las TICs. 


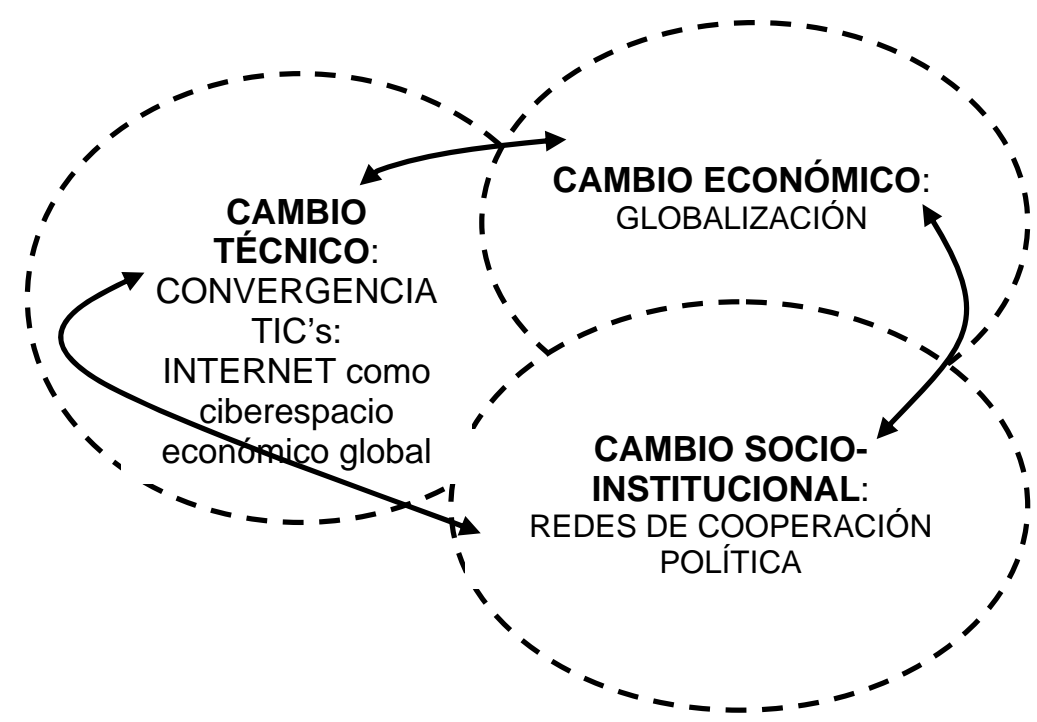

I lustración 1. Procesos de cambio del paradigma tecno-económico basado en las tecnologías de información y comunicación. Fuente: Marquina (2007:64).

\section{i) El cambio tecnológico: la convergencia de las TICs y el desarrollo de Internet}

El desarrollo de las TICs ha venido evolucionando desde la Segunda Guerra Mundial. Dichos desarrollos tecnológicos permitieron a la comunicación permanente entre las fuerzas aliadas. Una vez terminado este conflicto internacional, los Estados Unidos diseñaron un proyecto de investigación tecnológica que consistía en crear una red descentralizada de comunicación entre los países miembros de la OTAN. Era fundamental que dicha red estuviera descentralizada para que, en caso de ataque a algún país por parte del bloque socialista, no se perdiera la comunicación entre los otros aliados. Fue así que desde finales de la década de los años 60 se comenzó a desarrollar una infraestructura de comunicaciones denominada ARPANET, dirigida por el Departamento de Defensa de los Estados Unidos de América, a través de ARPA (Advanced Research Projects Agency). Consistía en una serie de enlaces que unían redes computarizadas, para lo cual fue necesario el establecimiento de ciertas reglas o pautas de operación (protocolos de comunicación) ${ }^{4}$ para que permitieran establecer la comunicación entre las máquinas aunque éstas estuvieran en escenarios físicos distantes.

\footnotetext{
${ }^{4}$ Un protocolo de comunicaciones es un conjunto de reglas que emplean dos o más equipos informáticos para dialogar entre sí, de forma que puedan establecer y mantener una comunicación libre de errores. Internet utiliza el protocolo de comunicaciones TCP/IP (Transmission Control Protocol/Internet Protocol)el cual asigna a cada máquina conectada a la red un número único, una dirección IP, como por ejemplo 234.721.13.19 que la identifica y le permite comunicarse. TCP/IP es el protocolo base de todas las máquinas y software sobre el que trabaja Internet.
} 
REDES- Revista hispana para el análisis de redes sociales

Vol.17,\#5, Diciembre 2009

http: // revista-redes.rediris.es

Si bien estos son los antecedentes de Internet, cabe señalar que para la creación de esta gran red de redes fue necesario el desarrollo de otro tipo de innovaciones tecnológicas en los sectores de la micro-electrónica, las telecomunicaciones y la informática.

El gran salto en la microelectrónica se da en 1971 con la invención del microprocesador. El microprocesador es un dispositivo de computación miniaturizado de gran capacidad para almacenar y procesar información que se ha venido desarrollando desde entonces, haciendo cada vez más potentes y pequeñas las computadoras personales. Paralelamente, se registraron grandes avances en la creación de lenguajes de programación así como en los medios y formas de transmisión de datos digitales. En este sentido, se desarrollaron las redes de conmutación por paquetes ${ }^{5}$ que permiten la conexión de equipos entre sí por medio de la utilización de protocolos específicos. Antes de operar con protocolos normalizados, cada fabricante establecía los procedimientos de comunicación de sus equipos, con lo cual era casi imposible conectar equipos de distintos fabricantes (y por ello, la comunicación se limitaba sólo entre los que tenían los mismos protocolos, que no necesariamente eran compatibles). Esta situación hizo necesario el establecimiento de protocolos normalizados, como el TCP/IP, que permitien la conexión entre los equipos independientemente de quién los fabrique, permitiendo así la interoperabilidad entre las computadoras, siendo ésta una de las características más valoradas por los usuarios de Internet.

La industria del software es de vital importancia para la interoperabilidad entre las redes informáticas, ya que estas innovaciones son las que permiten que se desplieguen los contenidos de información que transitan por esas redes. El establecimiento y uso de estándares técnicos es la piedra fundamental para la facilitación del comercio electrónico a través de Internet. La posibilidad de la interoperabilidad entre las máquinas permite agilizar las operaciones diarias de las empresas con sus socios, clientes y entidades de gobierno por lo que el comercio en Internet es posible a nivel global, al menos técnicamente.

\footnotetext{
${ }^{5}$ En este tipo de redes los datos a transmitir se dividen en trozos en el origen, denominados paquetes, y vuelven a agruparse en el destino una vez que todos ellos han sido recibidos correctamente. Para realizar el transporte y el control de los paquetes, el protocolo que se ideó fue el TCP/IP El protocolo TCP divide en paquetes los mensajes generados en origen, asignándoles un número de secuencia y la dirección de destino, en tanto que IP se ocupa del direccionamiento de los paquetes (del transporte), que pueden recorrer el camino por rutas diversas, incluso con tecnologías diferentes.
} 
REDES- Revista hispana para el análisis de redes sociales

Vol.17,\#5, Diciembre 2009

http: // revista-redes.rediris.es

En la mayoría de los casos, cada software es diseñado y patentado por su fabricante, aunque también existe lo que se conoce como software libre, en el cual el código informático no es propiedad de ningún particular, por lo que se puede acceder a él e incluso, modificarlo para hacer las adecuaciones necesarias para las que se utilizará. Desde el inicio de este sector económico, las empresas de software compiten en un mercado mundial que carece de estándares técnicos consolidados y reconocidos universalmente, por lo que todas las grandes compañías buscan innovar los mejores estándares para que sean éstos los que se impongan al resto del sector. El desarrollo de aplicaciones informáticas ha llegado a ser tan relevante que en algunos países como los Estados Unidos se pueden patentar, vía software, los modelos de negocios de la economía digital, por lo que ninguna otra empresa puede reproducir el mismo modelo de negocio si éste ha sido patentado a través de la creación de un software, situación que ha causado una gran controversia en el ambiente de los negocios electrónicos.

\section{ii) El cambio económico: TICs en el proceso de globalización}

La globalización, entendida como la internacionalización del capital y la segmentación de la producción distribuida en distintos países, sería impensable sin los desarrollos tecnológicos y la convergencia tecnológica de las TICs. En la fase de globalización del capitalismo mundial, el principal reto de las empresas es llegar con rapidez al mercado, ofreciendo nuevos productos y servicios a un costo menor, lo que les permite fortalecer sus ventajas comparativas y competitivas y por ende, tener una mayor rentabilidad de sus inversiones. Es en este punto que el comercio electrónico cobra gran relevancia ya que facilita el intercambio de información entre las empresas y sus clientes a fin de agilizar los procesos de comercialización y distribución de las mercancías a nivel mundial.

La necesidad de la facilitación comercial se ha incrementado en los últimos años como consecuencia del proceso de globalización. El desarrollo del comercio electrónico en Internet permite el intercambio de información en tiempo real no sólo entre las compañías y sus clientes sino también entre las empresas y los organismos relacionados con las operaciones de comercio exterior, durante las 24 horas de los 365 días del año. Por lo que esta aplicación de Internet reduce significativamente los tiempos de circulación de las mercancías y con ello, los ciclos del capital. 
REDES- Revista hispana para el análisis de redes sociales

Vol.17,\#5, Diciembre 2009

http: // revista-redes.rediris.es

Según la Organización Mundial de Comercio (OMC), la facilitación del comercio es la simplificación y armonización de los procedimientos que rigen el comercio internacional (CEPAL, 2005:2). Esta definición se refiere a una gran variedad de acciones tales como los procedimientos de importación y exportación (por ejemplo, los trámites en aduana o la obtención de licencias); las formalidades propias del transporte; los pagos, seguros y demás exigencias financieras. Pero ¿cuáles son los beneficios de la facilitación del comercio internacional? Entre los beneficios más palpables se podría mencionar la reducción del tiempo en los trámites y los procedimientos administrativos que generan importantes costos de transacción para las empresas por lo que reducir estos costos impactaría favorablemente en la fijación de los precios de las mercancías, situación que teóricamente, beneficia al consumidor final.

De este modo, el comercio electrónico permite el intercambio permanente de información entre los agentes económicos y gubernamentales, contribuyendo a mejorar la posición competitiva de las empresas y economías nacionales. Las mejores prácticas empresariales se basan en la asimilación de las tecnologías de información y particularmente de Internet, ya que es esta tecnología lo que les permite su proyección global. El intercambio de información entre las empresas es uno de los pilares de la competitividad a la que se enfrentan las compañías en el mercado global, por lo que es pues, un elemento crucial para su posicionamiento en los mercados internacionales del siglo XXI.

El rápido crecimiento de Internet se debe al conjunto de operaciones que se pueden ofrecer a través de esta gran red, como son servicios de mercadotecnia, de enlace comercial, de venta y distribución, de salud, de educación, de entretenimiento, además de diversos servicios gubernamentales. Es esta particularidad de Internet lo que ha provocado la emergencia de un nuevo espacio económico global que rebasa las fronteras geo-políticas ${ }^{6}$ de los Estados-nación y que motiva la participación de distintos actores sociales para la solución de las problemáticas

\footnotetext{
${ }^{6}$ Desde el enfoque de la geo-política mundial, el espacio es un factor de riqueza y de poder, por lo tanto, un espacio económico y político cuya composición y transformaciones generan cambios en la organización del sistema internacional. Graciela Arroyo afirma que los grandes cambios en la organización del sistema internacional registrados a través del tiempo son observables, principalmente por la recomposición de los espacios geográficos y por el ascenso y descenso de potencias hegemónicas, así como por las alianzas entre los Estados y demás actores existentes en cada época (Arroyo, 1999). Si bien la autora se refiere a los espacios físicos (geográficos), nosotros podemos extrapolar esta afirmación a los espacios virtuales como Internet, e indagar la manera en que la creación de este espacio tecno-económico y político se constituye y los cambios que genera Internet en la organización del sistema internacional, tanto a nivel económico como político.
} 
REDES- Revista hispana para el análisis de redes sociales

Vol.17,\#5, Diciembre 2009

http: // revista-redes.rediris.es

globales que plantea el desarrollo de esta tecnología para favorecer los procesos de globalización de la economía mundial.

La redefinición social de Internet como un espacio eminentemente económicocomercial de alcance global, ha provocado una transformación en las formas de actuación y cooperación entre los actores internacionales involucrados en la construcción del ciberespacio. Esta transformación socio-institucional está relacionada con el surgimiento de novedosas formas de organización política que reflejan el cambio de paradigma tecno-económico basado en las tecnologías de información y comunicación. La formación de redes políticas trasnacionales en las que participan actores heterogéneos es un fenómeno característico del cambio socio-institucional del nuevo paradigma tecnológico.

\section{iii) El cambio socio-institucional: la formación de redes trasnacionales de cooperación política}

De acuerdo con Carlota Pérez, el cambio socio-institucional del nuevo paradigma tecno-económico se constituye como un conjunto de criterios y principios para el diseño organizativo e institucional tanto al interior de las empresas como del contexto económico-político e institucional en el que operan (2003:42). Este contexto político-institucional en el que se construye el ciberespacio está caracterizado por la descentralización del poder político, la formación de redes políticas entre actores públicos y privados, la colaboración entre diversas organizaciones y la búsqueda de consensos para legitimar el ejercicio de autoridad. Podríamos decir que estos son algunos de los principios que conforman el nuevo paradigma tecno-económico. En realidad, el cambio socio-institucional se desarrolla cuando el nuevo paradigma rebasa los límites de la esfera tecnológica y permea las estructuras económicas, político-culturales e institucionales de las sociedades. Es así que los cambios socio-institucionales del nuevo paradigma tecno-económico podemos entenderlos como las nuevas formas de organización política basadas en redes de cooperación entre actores públicos y privados, lo que es reflejo de la descentralización del poder político que antes se encontraba en manos del Estado.

La creciente interdependencia de las economías nacionales y la conducción del proceso de globalización por parte de las empresas trasnacionales han obligado a los Estados a replegarse de su función reguladora en el mercado (Strange, 1996). Los planteamientos neoliberales afirman que el Estado no debe intervenir en la economía y que son las empresas quienes deben auto-regularse. Esta situación 
REDES- Revista hispana para el análisis de redes sociales

Vol.17,\#5, Diciembre 2009

http: // revista-redes.rediris.es

genera un cambio en la estructura del sistema internacional ya que la participación de las empresas trasnacionales en la definición de las políticas económicas internacionales ha venido a alterar los centros de poder en la sociedad mundial al desplazar a los Estados como únicos interlocutores en el escenario internacional.

En la actualidad, las políticas internacionales no se diseñan únicamente a partir de la negociación entre los Estados-nación, sino de la concurrencia de actores estatales y no estatales que buscan resolver una problemática común que a todos afecta. El cambio tecnológico por ejemplo, suscita la cooperación entre diversos actores internacionales para resolver las problemáticas que se generan en el proceso de construcción del nuevo paradigma tecno-económico. La introducción de Internet en los negocios ha generado una serie de riesgos que es necesario afrontar.

La complejidad de los riesgos de Internet implica una mayor cooperación entre los actores internacionales involucrados. Las problemáticas que se presentan por el desarrollo de Internet como un espacio económico global no son exclusivamente de carácter técnico sino también político, económico, jurídico y social ${ }^{7}$. Hemos observado que ante las problemáticas que emergen por el desarrollo del ciberespacio se han ido conformando redes políticas que toman la forma de esferas de autoridad ya que sus miembros inciden conjuntamente en el proceso de toma de decisiones que intervienen en la solución de las distintas problemáticas del comercio en Internet.

En torno a cada una de las problemáticas globales que emergen por el desarrollo del comercio en Internet, se conforma una determinada red de actores políticos que establecen sus propios mecanismos de coordinación política para resolver las problemáticas planteadas del nuevo paradigma tecno-económico de la sociedad mundial. Estos mecanismos de cooperación política que crean los actores internacionales para afrontar los riesgos del comercio en Internet no son acuerdos o tratados internacionales firmados por los gobiernos de los Estados. Son memoranda de entendimiento que firman las organizaciones internacionales en las

\footnotetext{
${ }^{7}$ Para profundizar en la complejidad del comercio en Internet, consultar Marquina, M.L., (2007).
} 
REDES- Revista hispana para el análisis de redes sociales

Vol.17,\#5, Diciembre 2009

http://revista-redes.rediris.es

que en muchas ocasiones, las empresas trasnacionales y sus asociaciones internacionales desempeñan un papel muy activo ${ }^{8}$.

En la última sección de este artículo veremos cómo la interoperabilidad, considerada como una problemática técnica que presenta el comercio electrónico en Internet, ha dado pie a la formación de una red de cooperación política trasnacional formada por actores públicos y privados, en la que los Estados sólo están presentes a través de su participación en los organismos internacionales.

\section{I. I mportancia de la interoperabilidad de los negocios electrónicos en el capitalismo global}

Una de las problemáticas técnicas que presenta el desarrollo de Internet como un espacio económico global es la creación de un lenguaje universal para los negocios electrónicos que permita el libre tránsito de información comercial a escala global.

La creación de un espacio económico global sustentado en Internet, sólo es posible si se concibe al ciberespacio como un mercado global que se construye a partir del principio de interoperabilidad entre las redes informáticas. Este principio consiste en el desarrollo de estándares universales, no propietarios, que aseguren, al menos técnicamente, el libre flujo de información a través de Internet. El respeto a este principio bajo el cual fue construida la gran red de redes en los años 70, permite que las operaciones comerciales que se realizan por todo el mundo puedan agilizarse y controlarse mejor, sin pasar por obstáculos técnicos que dificulten o hagan imposible el flujo de información a escala global.

En este sentido, la posibilidad de crear Internet como un espacio económico global se ve obstaculizada porque las empresas TICs que han incursionado en las prácticas del comercio electrónico han desarrollado lenguajes de codificación que no son compatibles entre sí. Mientras un grupo de empresas, apoyadas por su socio tecnológico, sea éste Microsoft, IBM, Commerce One o cualquier otro, establecen sus propios códigos para intercambiar información comercial, otro conjunto de empresas hacen lo propio con otros socios tecnológicos, lo cual ocasiona que los usuarios de Internet no puedan realizar transacciones comerciales con cualquier

\footnotetext{
${ }^{8}$ Los trasnacionalistas también argumentan que debido al acelerado desarrollo científico-tecnológico de la sociedad internacional contemporánea, es inevitable la creación de redes trasnacionales compuestas por técnicos expertos, altos ejecutivos y funcionarios públicos para atender la complejidad de los problemas actuales (Gilpin, 2002: 245).
} 
REDES- Revista hispana para el análisis de redes sociales

Vol.17,\#5, Diciembre 2009

http: // revista-redes.rediris.es

empresa del mundo y en cualquier momento. Esta situación ha provocado una "Torre de Babel" en el comercio electrónico que impide el libre flujo de información comercial y obstaculiza los procedimientos administrativos, propios del comercio internacional ${ }^{9}$.

La interoperabilidad entre las redes de Internet posibilita la construcción de un espacio económico global en el que se puedan realizar nuevos negocios y, al mismo tiempo, agilizarse las transacciones comerciales internacionales. De ahí la relevancia que tiene el código informático para la creación de un lenguaje universal y sus repercusiones en los negocios digitales de la economía mundial.

Las especificaciones técnicas para que los contenidos de Internet puedan fluir libremente por el ciberespacio se refieren al código informático que permite almacenar y transmitir los datos, o sea, la información. El código es un conjunto de especificaciones técnicas muy importante en el funcionamiento de las computadoras ya que a partir de los códigos se construyen las aplicaciones informáticas. El código está presente en los programas, protocolos e instrucciones que controlan el funcionamiento de los equipos informáticos. Dichos programas están compuestos de complejas combinaciones de códigos binarios con los que se crean lenguajes de programación, sistemas operativos, hojas de cálculo, procesadores de texto, bases de datos, protocolos de Internet, páginas web y todas las especificaciones necesarias para el funcionamiento de las computadoras, los servidores, los centros de datos informáticos y las redes de comunicación informática que componen el ciberespacio. Todo programa funciona según las especificaciones establecidas por los códigos que escriben los programadores, de manera que el código informático determina lo que el usuario puede o no puede hacer en cualquier equipo informático o en Internet (I báñez, 2002).

El código informático puede parecer una cuestión meramente técnica pero deja de serlo cuando se consideran los efectos sociales, económicos y políticos generados por la utilización de determinados programas informáticos cuyas características han sido definidas y decididas por algunos agentes económicos que persiguen sus intereses particulares como son las empresas trasnacionales.

\footnotetext{
${ }^{9}$ Marquina, M.L., (2006: 314).
} 
REDES- Revista hispana para el análisis de redes sociales

Vol.17,\#5, Diciembre 2009

http: // revista-redes.rediris.es

Lawrence Lessig señala que "si las computadoras e Internet funcionan de una determinada manera es porque alguien así lo ha decidido, no porque ésa sea la única o la mejor forma posible de funcionamiento". Lessig afirma que la arquitectura del ciberespacio y las tecnologías de información constituyen una fuente de poder y que, al analizar el papel político del código informático en las relaciones que se establecen en el ciberespacio, se va más allá de los aspectos estrictamente técnicos (L. Lessig, citado en Ibáñez, 2002: 105).

Lessig establece en un plano análogo al código informático y al código legal, pues en el ciberespacio el código informático actúa como regulador con la misma eficiencia que en la sociedad puede hacerlo el derecho: "La arquitectura es una especie de Derecho: determina lo que la gente puede o no puede hacer. Cuando los intereses comerciales determinan la arquitectura, están creando una especie de derecho privatizado (.....). Habitualmente, cuando nos referimos a conjuntos de valores opuestos y a las opciones que hacemos por uno de ellos, decimos que estas opciones son políticas. Son opciones sobre el ordenamiento del mundo y sobre la priorización de valores. Opciones entre valores, opciones sobre la regulación, sobre el control, opciones sobre la definición de espacios de libertad - de todo ello se ocupa la política-. El código codifica valores y, sin embargo, resulta curioso que la mayoría de la gente se refiera al código como si fuese una mera cuestión de ingeniería. O como si fuese mejor dejar el código en manos del mercado. O mejor, mantenerlo al margen del gobierno (....). Si el código es Derecho, entonces el control del código es poder.(...) el código se está convirtiendo en un terreno de rivalidad política crucial ¿quién debería escribir ese software que estructura cada vez más nuestras vidas diarias?(...) Los programadores se están convirtiendo en legisladores (L. Lessig, citado en Ibáñez, 2002: 105).

Recordemos que Internet surgió con una arquitectura abierta. Los programadores que contribuyeron a su diseño permitieron el libre acceso al código fuente de los programas y protocolos (TCP/IP, HTTP, HTML, etc.) y fue, bajo ese principio que se creó Internet por la comunidad de académicos involucrados en su desarrollo. También se desarrollaron algunos sistemas operativos y programas informáticos a cuyo código fuente se puede acceder libremente como Linux o Java, al mismo tiempo que se desarrollaron códigos propietarios como los que operan en ambiente Windows. Frente al software libre (free software) o al software de fuente abierta (open-source software), propugnados por muchos investigadores y activistas 
REDES- Revista hispana para el análisis de redes sociales

Vol.17,\#5, Diciembre 2009

http: // revista-redes.rediris.es

informáticos, algunas de las principales empresas de software son partidarias de programas propietarios (propietary software) en los que sólo tiene acceso al código fuente la propia empresa que lo ha creado y comercializado, como es el caso de Microsoft y de la mayoría de las compañías de software (I báñez, 2002).

Determinar si el código informático que se utiliza en el comercio en Internet debe ser transparente, abierto y accesible a todos, es decir, preservar su universalidad, ha sido motivo de fuertes controversias pero también ha generado la cooperación entre actores internacionales diversos que, a pesar de su heterogeneidad, son complementarios por las funciones que realizan y porque persiguen metas comunes.

La entrada de las empresas al ciberespacio ha favorecido las posiciones de compañías trasnacionales de informática que, guiadas únicamente por intereses comerciales, han defendido la idea de que en Internet se trabaje con código propietario, lo cual genera tres situaciones: a) por una parte el código, es decir, el lenguaje, se ha convertido en una mercancía que muchos desean poseer para lucrar con ella; b) la propiedad privada sobre el código genera una mayor dependencia tecnológica de las pequeñas compañías usuarias respecto a sus grandes proveedores tecnológicos y, c) al violarse el principio de interoperabilidad y universalidad en el ciberespacio, se pone en riesgo la facilitación del comercio internacional la cual favorece el proceso de globalización y la competitividad de la economía mundial.

Para resolver estas controversias y asegurar la interoperabilidad en las prácticas de comercio electrónico, la Organización de las Naciones Unidas, a través de la Comisión Económica para Europa $\left(\right.$ UNECE) ${ }^{10}$ y en colaboración con las organizaciones internacionales especializadas en la elaboración de estándares internacionales como la Comisión Electrotécnica Internacional (IEC) y la Organización de Estándares Internacionales (ISO) firmaron en 1995 un Memorando de Entendimiento mediante el cual se reconocen mutuamente como autoridades

\footnotetext{
${ }^{10}$ La guerra de estándares que se suscita en este nuevo paradigma tecno-económico de las TICS ha motivado que las Naciones Unidas, a través de la Comisión Económica para Europa (y Norteamérica) haya creado desde 1972, un grupo de trabajo dedicado a la elaboración de estándares que rijan el intercambio electrónico de datos. Es así que se desarrollaron los primeros estándares internacionales EDI (Electronic Data Interchange) para diseñar los sistemas de información que pudieran permitir el intercambio electrónico de datos durante las operaciones comerciales entre empresas altamente integradas y ubicadas en distintos territorios nacionales. Con la creación de lo estándares EDI se inicia la era del comercio electrónico.
} 
REDES- Revista hispana para el análisis de redes sociales

Vol.17,\#5, Diciembre 2009

http: // revista-redes.rediris.es

legítimas para impulsar y desarrollar los estándares internacionales que aseguren la interoperabilidad de los negocios en el ciberespacio. Cabe indicar que la Unión Internacional de Telecomunicaciones (ITU) se vinculó formalmente a esta red política tres años después, al igual que los grupos de usuarios, situación que motivó el reemplazo del primer Memorando de Entendimiento.

\section{Formación de la red trasnacional de cooperación política para la interoperabilidad de los negocios electrónicos}

La creación de estándares internacionales para los negocios electrónicos implica la interrelación de actores internacionales altamente especializados pero cuya heterogeneidad funcional les obliga a emprender acciones conjuntas de cooperación a fin de alcanzar la meta común que comparten y que los hace cooperar: asegurar la interoperabilidad entre las transacciones electrónicas para favorecer la facilitación del comercio mundial y con ello, impulsar el proceso de globalización.

Al realizar esta investigación identificamos a más de una decena de organizaciones especializadas en elaborar estándares técnicos relacionados con las TICs, sin embargo, para el presente trabajo hemos seleccionado sólo a aquéllas organizaciones que cumplen con dos criterios esenciales: a) que tengan un alcance internacional $y, b)$ que se reconozcan mutuamente como autoridades legítimas para desarrollar y fijar los estándares internacionales para los negocios electrónicos.

Fue así que identificamos a cuatro actores internacionales que suscribieron el Memorando de Entendimiento relativo a la estandarización en el área de los negocios electrónicos y son: el Centro para la Facilitación del Comercio y los Negocios Electrónicos (UNECE/CEFACT), la Organización de Estándares Internacionales (ISO), la Comisión Electrotécnica Internacional (IEC), la Unión Internacional de Telecomunicaciones (ITU). En calidad de participantes y como representantes de las empresas y organizaciones usuarias del comercio electrónico global se encuentran CALS International, NATO CALS Organisation, y la Organización de Promoción de Estándares para la Estructuración de la Información (OASIS). 
REDES- Revista hispana para el análisis de redes sociales

Vol.17,\#5, Diciembre 2009

http: //revista-redes.rediris.es

\begin{tabular}{|c|c|}
\hline Organización I nternacional & Misión institucional \\
\hline $\begin{array}{l}\text { Centro para la Facilitación del } \\
\text { Comercio y los Negocios } \\
\text { Electrónicos (UNECE/CEFACT) }\end{array}$ & $\begin{array}{l}\text { Forma parte de la Comisión Económica para Europa de las Naciones } \\
\text { Unidas (UNECE). Su misión es generar mecanismos efectivos, } \\
\text { sencillos y transparentes para facilitar, mediante la armonización, } \\
\text { los procedimientos relacionados con el comercio internacional y, en } \\
\text { particular, con los negocios electrónicos a nivel global. }\end{array}$ \\
\hline $\begin{array}{l}\text { Organización Internacional } \\
\text { para la Estandarización, (ISO) }\end{array}$ & $\begin{array}{l}\text { Establecer normas técnicas internacionales y promover su } \\
\text { armonización con las normas nacionales (establecidas en cada país) } \\
\text { a fin de facilitar el comercio mundial, el intercambio de información } \\
\text { y contribuir a la transferencia de tecnología mediante la aprobación } \\
\text { de estándares internacionales. }\end{array}$ \\
\hline $\begin{array}{l}\text { Comisión Electrotécnica } \\
\text { Internacional (IEC) }\end{array}$ & $\begin{array}{l}\text { Asegurar el uso y conformidad hacia los estándares internacionales } \\
\text { establecidos mediante consenso por sus miembros. }\end{array}$ \\
\hline $\begin{array}{l}\text { Unión Internacional de } \\
\text { Telecomunicaciones (ITU) }\end{array}$ & $\begin{array}{l}\text { Fomentar la cooperación internacional y lograr consensos entre el } \\
\text { sector privado y los gobiernos; promover el desarrollo de la } \\
\text { infraestructura; establecer estándares para la construcción e } \\
\text { interoperabilidad de las redes; asignar las bandas de frecuencia de } \\
\text { las telecomunicaciones; recomendar las tarifas por uso de las redes } \\
\text { electromagnéticas; elaborar estudios técnicos y de mercado de las } \\
\text { telecomunicaciones; diseñar las políticas de competencia del sector } \\
\text { y, emitir recomendaciones a gobiernos y empresas. }\end{array}$ \\
\hline $\begin{array}{l}\text { Organización de Promoción de } \\
\text { Estándares para la } \\
\text { Información Estructurada } \\
\text { (OASIS) }\end{array}$ & $\begin{array}{l}\text { Crear estándares internacionales utilizando el lenguaje XML, a fin de } \\
\text { asegurar la interoperabilidad en los negocios electrónicos }\end{array}$ \\
\hline CALS International & $\begin{array}{l}\text { Desarrollar y consensuar los estándares internacionales que se } \\
\text { requieren para los negocios electrónicos entre las distintas } \\
\text { organizaciones industriales a nivel internacional. }\end{array}$ \\
\hline NATO CALS Organisation & $\begin{array}{l}\text { Impulsar la cooperación en el seno de la Organización del Tratado } \\
\text { del Atlántico Norte (NATO) para el desarrollo de estándares en el } \\
\text { comercio digital de la industria militar. }\end{array}$ \\
\hline
\end{tabular}

Tabla 1. Organizaciones internacionales.

El estudio de esta red política lo hemos elaborado considerando algunos elementos

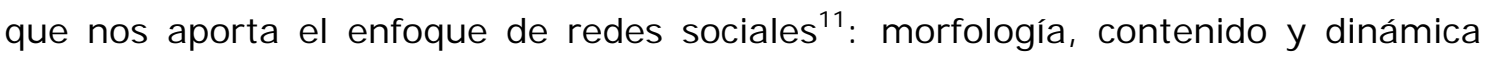
Casas, R. (2003). A través del ARS es posible conocer las estructuras sociales, a partir del análisis de las interacciones que se establecen entre un número determinado de actores que integran la red en estudio. En este sentido, aplicamos en nuestro trabajo el concepto de redes para analizar el tipo de relaciones entre los diversos actores internacionales y los recursos de poder que se intercambian en el proceso de construcción de los estándares internacionales para los negocios electrónicos.

\footnotetext{
${ }^{11}$ El análisis de redes sociales (ARS) es una metodología que nos permite crear objetos de conocimiento a partir de la construcción de redes, con el propósito de analizar las relaciones que se establecen entre los actores y las estructuras sociales que a partir de dichas interacciones se generan. Para una mayor comprensión sobre los fundamentos y usos de esta metodología se recomienda la lectura de Molina, J.L., El análisis de redes sociales. Una introducción, Barcelona, Ediciones Bellaterra, 2001.
} 
REDES- Revista hispana para el análisis de redes sociales

Vol.17,\#5, Diciembre 2009

http: // revista-redes.rediris.es

Para ello, en este apartado analizamos la morfología de esta red política a partir de identificar a los actores sociales que la integran y la meta común que comparten, toda vez que en el primer apartado de este artículo, expusimos el contexto socioinstitucional en el que se construye esta red política caracterizado por la descentralización del poder político. El contenido de esta red radica en el análisis de las interacciones que establecen los actores internacionales que hemos seleccionado. Por último, la dinámica la hemos considerado a partir del nivel de formalidad que ha adquirido esta red a través del tiempo y con la participación de nuevos actores.

A continuación presentamos a los actores internacionales que integran esta red política y que tienen como meta común asegurar la interoperabilidad de las transacciones comerciales en el nuevo espacio económico global generado por Internet. Asimismo, resaltamos los objetivos institucionales y el papel que desempeña cada uno de estos actores en esta red:

i) Centro para la Facilitación del Comercio y los Negocios Electrónicos (CEFACT), fue creado en 1997 al interior de la Comisión Económica para Europa de las Naciones Unidas (UNECE). La UNECE es una de las cinco comisiones regionales que pertenecen al Consejo Económico y Social de las Naciones Unidas (ECOSOC) y su objetivo es promover la integración económica paneuropea e incrementar la cooperación económica y comercial con Norteamérica (EUA y Canadá) así como proponer a los gobiernos recomendaciones sobre políticas de armonización y estandarización. Con este propósito fue creado el UNECE/CEFACT.

Este Centro, como su nombre lo indica, está encargado de velar por la facilitación de las operaciones comerciales a escala global, por lo que buscar la interoperabilidad entre las redes que conforman Internet a partir de crear un lenguaje universal para los negocios electrónicos, es parte de su misión. Pero la interoperabilidad no es un asunto que pueda resolverse únicamente al interior del UNECE/CEFACT o incluso entre los organismos del sistema de las Naciones Unidas, debido a la alta especificidad técnica que se requiere para crear un lenguaje binario estandarizado y de libre acceso ${ }^{12}$. Por lo que el UNECE/CEFACT no es el único actor

12 Este Centro está organizado por grupos de trabajo específicos. Uno de esos grupos (Applied Technologies Group, ATG) es de vital importancia en el comercio electrónico global ya que su misión consiste en diseñar la sintaxis para la estructura de los documentos digitales con efectos comerciales, legales y administrativos, basados en estándares universales. Por ello, este grupo de trabajo contribuyó con la UNCITRAL para crear la Ley Modelo del Comercio Electrónico, junto con otro grupo de trabajo 
REDES- Revista hispana para el análisis de redes sociales

Vol.17,\#5, Diciembre 2009

http: // revista-redes.rediris.es

internacional que participa en la creación de los estándares internacionales para los negocios electrónicos. Existen otras organizaciones internacionales a las que la UNECE ha convocado para que se sumen a la iniciativa de Naciones Unidas de crear un código específico para los negocios electrónicos que pretende ser universal ${ }^{13}$ y no propietario. Algunas de estas organizaciones se han formado desde sus orígenes con representantes del sector privado y gubernamental bajo el principio de cooperación y complementariedad entre ambos. Tal es el caso de la Comisión Electrotécnica Internacional (IEC), la Organización de Estándares Internacionales, ISO y la Unión Internacional de Telecomunicaciones (ITU).

ii) Comisión Electrotécnica Internacional (IEC): es una organización internacional de normalización en los campos eléctrico, electrónico y tecnologías relacionadas (magnetismo, electromagnetismo, electroacústica, multimedia, telecomunicaciones y producción y distribución de energía), fundada desde 1906. La IEC es responsable de la estandarización de todo tipo de equipos eléctricos y áreas relacionadas. Por ello, es considerada como el brazo técnico de la OMC en materia de definición de estándares en las áreas mencionadas. Los estándares internacionales que produce la IEC buscan remover las barreras técnicas al comercio internacional y facilitar las transacciones comerciales, de ahí su estrecha vinculación con la generación de estándares para el comercio electrónico global.

IEC está integrada por los organismos nacionales de normalización. Algunos de estos organismos de normalización son privados, otros públicos y otros más mixtos (es decir, con participación pública y privada). Como comentamos anteriormente, su misión es difundir y asegurar el uso y conformidad hacia los estándares internacionales establecidos mediante consenso por sus miembros. Están representados en la IEC más de 60 países $^{14}$.

Los organismos nacionales de normalización de la IEC han aceptado el Código de Buenas Prácticas para la Preparación, Adopción y Aplicación de los Estándares Internacionales. Dicho código forma parte del Acuerdo sobre Barreras Técnicas al Comercio (Technical Barriers to Trade, TBT), mediante el cual, los cien gobiernos

encargado de los aspectos legales (Legal Group, LG) con quien también colaboró en el diseño de los documentos digitales para el comercio electrónico. Ver sitio http://www. unece.org/cefact

${ }^{13}$ El principio de universalidad es lo que se adiciona a la complejidad técnica del comercio en Internet ya que bajo este principio se busca asegurar el acceso a todo tipo de empresas y consumidores, sin que queden excluidos técnicamente de las redes globales de comercio.

${ }^{14}$ Ver sitio http://www.iec.ch/ 
REDES- Revista hispana para el análisis de redes sociales

Vol.17,\#5, Diciembre 2009

http: // revista-redes.rediris.es

signatarios reconocieron explícitamente que los estándares internacionales juegan un rol central para impulsar el desarrollo eficiente de las industrias eléctrica y electrónica así como el crecimiento del comercio internacional ya que un componente o un producto manufacturado bajo los estándares reconocidos por IEC puede ser vendido sin ningún obstáculo técnico en cualquier otro país del mundo que acepte dichos estándares.

Como un mecanismo para legitimar los estándares internacionales que produce la IEC, dicha Comisión trabaja en estrecha colaboración con la ISO para el desarrollo de numerosas normas técnicas (normas ISO/IEC). Con el fin de reforzar la cooperación entre ambas organizaciones y buscar consenso internacional entre las comunidades empresariales y gubernamentales, han establecido un Centro de Información ISO/IEC cuyo objetivo consiste en difundir los trabajos de ambas organizaciones así como proporcionar información específica a los interesados en los procesos de construcción de estándares y adopción de políticas para la estandarización de productos eléctricos, electrónicos y de tecnologías relacionadas.

iii) Organización de Estándares Internacionales (ISO): ${ }^{15}$ es una organización internacional no gubernamental fundada en 1997 y considerada desde entonces, como el órgano consultivo de la ONU en materia de estandarización. Está compuesta por los organismos de normalización nacionales (sean éstos privados o públicos), que producen normas internacionales industriales y comerciales. ISO coopera estrechamente con la Organización Mundial del Comercio (OMC), a través de su brazo técnico, la Comisión Electrotécnica Internacional (IEC), a fin de establecer las normas técnicas (estándares internacionales) para el sector eléctricoelectrónico, en un marco de autorregulación por parte de los grupos privados. Dichas normas técnicas se conocen como normas ISO y su finalidad es homologar las normas oficiales reconocidas en cada país con las normas internacionales acordadas por la ISO, en consonancia con el Acta Final constitutiva de la OMC.

Cabe señalar que la ISO y la IEC han creado un grupo de trabajo específico (el ISO/IEC/JTC1) encargado de promover la generación de estándares internacionales para TICS. Dicho grupo de trabajo, resultado de la cooperación entre la ISO y la IEC representa el vehículo de comunicación entre estas dos organizaciones especializadas en la elaboración de estándares internacionales para el área

${ }^{15}$ Ver sitio http://www.iso. org 
REDES- Revista hispana para el análisis de redes sociales

Vol.17,\#5, Diciembre 2009

http://revista-redes.rediris.es

eléctrica-electrónica. Con la creación de este grupo de trabajo, ambas organizaciones internacionales se comprometen a establecer una relación formal y periódica de cooperación para impulsar la aprobación de dichos estándares internacionales, evitando los procedimientos burocráticos que existen al interior de la ISO y la IEC para la toma de decisiones.

Con la creación de este grupo de trabajo se busca fortalecer las acciones que desarrolla UNECE/CEFACT para el diseño de estándares internacionales para los negocios electrónicos, a fin de que los estándares generados por este Centro o en colaboración con el mismo, sean reconocidos universalmente y adoptados más rápido en todos los países del mundo, a través del establecimiento de normas ISO.

En materia de comercio electrónico, la ISO ha emitido un paquete de normas internacionales relacionada con la transferencia de documentos comerciales y mensajes electrónicos, integradas bajo el rubro ISO 15000 (ebXML). Cabe resaltar que para el logro de estas normas, el UNECE/CEFACT participó activamente junto con OASIS, organización que se ha especializado en el uso del XML para el diseño de documentos comerciales digitales.

El nuevo reto de estas organizaciones es el desarrollo y aprobación de un lenguaje universal para los negocios electrónicos. Como ya comentamos, esta iniciativa la está impulsando fuertemente UNECE/CEFACT en estrecha colaboración con OASIS para facilitar las operaciones comerciales en todo el mundo, mediante la adopción de estándares internacionales para el comercio electrónico. Pero también consideramos que con esta iniciativa se frena la ventaja tecnológica de las compañías norteamericanas respecto a las europeas en el desarrollo de códigos informáticos ${ }^{16}$. De alguna manera, la propuesta de crear un lenguaje universal para los negocios electrónicos es una forma de asegurar la interoperabilidad y mayor competencia en el ciberespacio, al que puedan tener acceso las empresas de cualquier tamaño y país.

\footnotetext{
${ }^{16}$ FORTRAN, definido en la década de los años 50 en los Estados Unidos por IBM; COBOL creado en 1960 y patrocinado por el Departamento de Defensa de los Estados Unidos; el código ASCII desarrollado en 1963 por el Comité Estadounidense de Estándares; PL/I creado por IBM en esa misma década; BASIC desarrollado en Dartmouth Collage en 1965; PASCAL creado en 1970 en Estados Unidos por Nicklaus Wirth y JAVA desarrollado por Sun Microsystems a principios de la década de los años 90, por citar sólo algunos de los más importantes.
} 
REDES- Revista hispana para el análisis de redes sociales

Vol.17,\#5, Diciembre 2009

http: // revista-redes.rediris.es

Finalmente, cabe resaltar que tanto ISO como IEC trabajan en estrecha colaboración con la ITU. Por lo que la ISO, la IEC y la ITU son consideradas como las organizaciones internacionales especializadas en elaboración de estándares internacionales en las áreas de la electricidad, la electrónica y las telecomunicaciones. Sin embargo, ITU no participó en la firma del primer Memorando de Entendimiento para la estandarización en el área de los negocios electrónicos convocado por UNECE y celebrado en 1995 con la participación de la ISO, la IEC y la UNECE. Dada la fuerte presencia de compañías estadounidenses al interior de la ITU, esta organización internacional fue el actor internacional que más reservas tuvo para impulsar la creación de un código universal para los negocios electrónicos, ya que dichas empresas consideran a los lenguajes informáticos como estándares a partir de los cuales se desarrollan diversas aplicaciones informáticas, siendo estas mercancías altamente cotizadas. Por lo que aceptar que las empresas se deban ceñir al uso de un lenguaje universal, no propietario, les resta ventajas competitivas losl mercados.

iv) La Unión Internacional de Telecomunicaciones (ITU): es una organización internacional cuyos orígenes se remontan al siglo XIX y que desde su fundación, existe una estrecha colaboración entre el sector privado y público. En 1932 se adoptó al interior de esta organización internacional la Convención Internacional de Telecomunicaciones, por lo que en 1947, una vez creada la ONU, se conviene en uno de sus organismos especializados.

Los representantes del sector privado son compañías de telecomunicaciones, radio, instituciones financieras, centros de investigación y desarrollo, así como asociaciones empresariales. Los países que tienen mayor número de empresas que participan como miembros de este organismo especializado de las Naciones Unidas son: Estados Unidos, con una centena de instituciones; Japón (47); Reino Unido (29); Alemania (21); Italia (18); Egipto (16); Francia (15); China (13); Canadá (12); República de Corea (9), India (9), Jordania (8), Líbano (7); España (7), Países Bajos (7), Pakistán (6) y, Finlandia (5). En el caso de Egipto, la mayoría de las 16 compañías que se indican son empresas trasnacionales, principalmente inglesas y estadounidenses. Finalmente, entre las organizaciones internacionales presentes en la ITU se encuentra la ISO, lo que implica el mutuo reconocimiento y trabajo coordinado entre ambas instituciones internacionales involucradas en la definición de estándares internacionales. 
REDES- Revista hispana para el análisis de redes sociales

Vol.17,\#5, Diciembre 2009

http://revista-redes.rediris.es

En general, las normativas generadas por la ITU están contenidas en un amplio conjunto de documentos denominados recomendaciones. Las recomendaciones correspondientes son establecidas mediante el acuerdo entre empresas y gobiernos, sobre un mismo tema, por ejemplo el establecimiento de tarifas en las redes, su mantenimiento, los estándares técnicos para desarrollarlas y operarlas, etc. Aunque en las recomendaciones nunca se ordena, solo se recomienda, su contenido a nivel de las relaciones internacionales, es considerado como mandatorio por los gobiernos y empresas operadoras ${ }^{17}$. Su importancia radica en que ITU es la institución de Naciones Unidas encargada de hacer las recomendaciones a los gobiernos sobre la adopción de ciertos estándares internacionales en materia de telecomunicaciones.

Finalmente, tenemos a tres actores internacionales que representan a los grupos de usuarios del comercio electrónico: la Organización de Promoción de Estándares para la Estructuración de la Información (OASIS), CALS internacional y, NATO CALS Organisation.

v) Organización de Promoción de Estándares para la Estructuración de la Información (OASIS): es un consorcio internacional sin fines de lucro creado en 1993, que conduce el desarrollo, convergencia y adopción de estándares para los negocios electrónicos. Originalmente, esta organización fue fundada bajo el nombre de SGML Open (Standard Generalized Markup Language) ${ }^{18}$. Funcionaba como una comunidad de vendedores y usuarios dedicados a la promoción y desarrollo de pautas para la interoperabilidad, a través del uso del SGML. En 1998, el nombre legal de la organización fue cambiado a OASIS para reflejar mejor el amplio campo de trabajos técnicos que se realizan al interior de esta organización, incluyendo los estándares XML (Extensible Markup Languaje) ${ }^{19}$. Desde entonces se reconoce como

\footnotetext{
${ }^{17}$ Ver sitio http://www.itu.int/

${ }^{18}$ Los lenguajes de marcado son también denominados lenguajes de anotaciones o de etiquetas. Dichos lenguajes definen un conjunto de reglas para estructurar y dar formato a un documento electrónico. Suelen utilizar etiquetas para definir el inicio y el final de un elemento (un párrafo, un título, un elemento subrayado, etc.) Los lenguajes de marcado más utilizados son HTML y XML, ambos basados en el metalenguaje SGML. Obtenido de «http://enciclopedia.us.es/index.php/Lenguaje_de_marcado» EI SGML es un conjunto de reglas para hacer lenguajes de marcado, es decir, es un metalenguaje. Los lenguajes de SGML tienen ciertas reglas acerca de crear etiquetas y lo que se puede hacer con ellas.

${ }^{19}$ EI XML es un lenguaje de marcado que permite estructurar, intercambiar y reusar la información. En tanto que está basado en el metalenguaje SGML, tiene ciertas reglas para crear etiquetas y lo que se puede hacer con ellas. Estas reglas se encuentran definidas en un DTD (Document Type Definition) o Declaración de Tipo de Documento. Las etiquetas se encuentran en código ASCII o en UNICODE así que no existen problemas si el documento electrónico se visualiza en distintas plataformas o sistemas, ya que está desarrollado en código abierto (Galina, 2004). En un futuro, se pretende que la información
} 
REDES- Revista hispana para el análisis de redes sociales

Vol.17,\#5, Diciembre 2009

http: //revista-redes.rediris.es

el consorcio dedicado a crear estándares internacionales no propietarios, utilizando el $X M L^{20}$.

OASIS produce estándares mundiales ${ }^{21}$ para la seguridad, los servicios Web, las transacciones comerciales así como para la interoperabilidad entre los negocios y los mercados electrónicos. Esta labor es posible gracias a la participación de más de 3 mil expertos de todo el mundo que trabajan en empresas trasnacionales, medianas y pequeñas así como en centros de investigación y desarrollo, sin excluir la posibilidad de participación de aquéllos interesados en colaborar a título individual. OASIS reúne a empresas e ingenieros programadores de diversos países y cuenta además, con representantes de más de 100 países ubicados en los cinco continentes.

Esta organización ofrece a sus miembros un foro abierto de discusión sobre las necesidades del mercado y ofrece recomendaciones y directivas para acelerar la adopción, aplicación e implementación de estándares para estructurar la información que se intercambia a través de Internet. Su trabajo complementa la labor que realizan otros organismos internacionales como el UNECE/CEFACT - con quien colabora estrechamente-, la Comisión Electrotécnica Internacional (IEC), la Organización Internacional de Estándares (ISO) y la Unión Internacional de Telecomunicaciones (ITU), además de otras organizaciones dedicadas a la elaboración de estándares para Internet, como es el caso del consorcio $\mathrm{W}_{3} \mathrm{C}^{22}$.

esté en XHTML, en lugar de estar en HTML, a fin de que la información en el ciberespacio esté estructurada (ordenada) y sea posible su recuperación, intercambio y reuso.

${ }^{20}$ Ver sitio http://www. oasis-open.org

${ }^{21}$ Cabe señalar que la estandarización no inhibe los procesos de innovación, ya que únicamente se busca con ellos que la información pueda ser intercambiada en un marco de seguridad y con posibilidad de ser reutilizable a fin de obtener mayores beneficios de la misma.

${ }^{22}$ El W3C es un consorcio fundado por el creador de los protocolos de la World Wide Web, Tim BernersLee, en colaboración con el MIT, el Institut National de Recherche en Informatique Automatique y el Keiko Research Institute de Japón. Este consorcio tiene el propósito de crear protocolos comunes para asegurar la interoperabilidad en Internet. Ha tenido una participación relevante en el diseño de la arquitectura de Internet, la cual se ha ido construyendo bajo los siguientes principios que comparten los miembros del W3C: a) la interoperabilidad, entendida como la compatibilidad entre todas las especificaciones técnicas de los lenguajes y protocolos de la web así como la compatibilidad entre todos los programas o equipos utilizados para acceder a la misma; b) la adaptabilidad al cambio para poder acomodarse a las tecnologías futuras, por lo que sus diseños técnicos deben regirse por criterios de simplicidad, modularidad, compatibilidad y extensibilidad y c) la descentralización de la red que permite que la red funcione con mayor fluidez y menor vulnerabilidad. Estos principios tienen una gran repercusión sobre los diseños tecnológicos y las actividades comerciales que se realizan en Internet ya que a pesar de que son estándares voluntarios - como los de la ISO-, su adopción generalizada hace que se conviertan en normas técnicas que por su eficiencia, se convierten en normas legítimas en este sector. Una de las iniciativas más destacable de este actor internacional fue el lanzamiento en el año 2000 del estándar técnico para firmas digitales en lenguaje XML, que diseñó en colaboración con IETF (Internet Engineering Task Force). Dicho estándar ofrece garantías de seguridad y privacidad en las 
REDES- Revista hispana para el análisis de redes sociales

Vol.17,\#5, Diciembre 2009

http: // revista-redes.rediris.es

En realidad, todas las actividades que se realizan en OASIS procuran resolver las problemáticas técnicas relacionadas con el comercio electrónico en el entorno de Internet. Esta organización tiene una política de propiedad intelectual basada en el principio de que todos los estándares que se elaboran en OASIS están construidos con código abierto y ningún grupo de expertos o compañía es propietaria de los derechos ya que todos los estándares son de libre acceso y están a la disposición de cualquier empresa u organización.

Las innovaciones de OASIS en materia de comercio electrónico son trabajos que han sido respaldados por la ONU, a través de los vínculos estrechos que mantiene con el UNENE/CEFACT. Muestra de ello es que, desde 1999, a través del UNECE/CEFACT, la ONU patrocina junto con OASIS, la iniciativa ebXML (electronic business XML), siendo el desarrollo del UBL un componente esencial de dicha iniciativa ${ }^{23}$. En noviembre de 2004, OASIS aprobó la versión 1.0 del Universal Business Language como un estándar internacional.

OASIS es una organización que tiene un gran respaldo de la UNECE a través del CEFACT porque representa a la comunidad de tecnólogos que logra los consensos necesarios para el desarrollo y aprobación de estándares internacionales relacionados con el comercio digital. El lenguaje XML es impulsado por UNECE/CEFACT porque permite el reuso de la información, es decir, permite clasificar la información, lo que genera un valor agregado a la misma.

Los desarrollos tecnológicos de OASIS están presentes en el conjunto de normas ISO 15000 las cuales han sido desarrolladas utilizando el lenguaje XML.

vi) Continuous Acquisition and Lifecycle Support (CALS Internacional): es una organización no gubernamental de alcance mundial que se enfoca a desarrollar y consensar los estándares internacionales que se requieren para los negocios electrónicos entre las distintas organizaciones industriales a nivel internacional. Esta organización considera que el uso de estándares internacionales permite facilitar el intercambio de información comercial vía electrónica entre las empresas

transacciones comerciales a través de Internet (Ibáñez, 2002:438). Por esta razón, colabora estrechamente con UNECE/CEFACT y con OASIS, según quedó estipulado en el Memorando de Entendimiento al que ya nos hemos referido con anterioridad.

23 OASIS mantiene relación con otras organizaciones relacionadas con la creación de estándares internacionales ya que reconoce que ninguna organización puede hacerlo todo y considera que otros grupos tienen mucho que contribuir para el desarrollo de estándares técnicos. Por ello, mantiene 
REDES- Revista hispana para el análisis de redes sociales

Vol.17,\#5, Diciembre 2009

http: // revista-redes.rediris.es

a través de sus cadenas de proveeduría. Con dichos estándares se busca soportar las operaciones de los negocios electrónicos - para uso civil o militar- entre las empresas y sus clientes.

Esta organización ha desarrollado una metodología propia que busca mejorar la eficiencia de las organizaciones mediante el intercambio y reuso constante de la información electrónica, optimizando el tiempo, el costo y la precisión de la información comercial en las transacciones electrónicas. Este modelo permite la integración de las empresas a escala global facilitando el comercio electrónico a través del intercambio de información técnica y comercial dentro y entre las organizaciones.

CALS International ha colaborado estrechamente con la IEC, ISO, UNECE/CEFACT y NATO CALS Organisation en la detección de las necesidades de los distintos sectores industriales para realizar las transacciones digitales en un entorno global, para lo cual es indispensable el diseño de estándares internacionales que permitan la interoperabilidad entre los agentes económicos involucrados.

vii) NATO CALS Organisation: es una organización inter-gubernamental que promueve la cooperación en el seno de la Organización del Tratado del Atlántico Norte (NATO) para el desarrollo de estándares para el comercio electrónico con la industria militar. Busca establecer, en la medida de lo posible, estándares internacionales con sus socios comerciales para reducir costos para la producción de armamento. Trabaja en forma estrecha con CALS International, IEC, ISO y, UNECE/CEFACT en la detección de necesidades de estándares de comercio electrónico en la industria militar.

En la siguiente tabla hemos clasificado a estos siete actores internacionales según su origen, en tres tipos: a) de origen público (inter-gubernamental); b) de origen mixto (con participación privada y pública y, c), de origen privado; con el propósito de resaltar la heterogeneidad de los actores involucrados en esta red política. Cabe señalar que es precisamente esta heterogeneidad funcional la que motiva la cooperación entre los mismos para la consecución de su meta colectiva: el diseño de estándares internacionales para los negocios electrónicos que permitan un libre flujo de información y por ende, una reducción de costos gracias al intercambio 
REDES- Revista hispana para el análisis de redes sociales

Vol.17,\#5, Diciembre 2009

http: // revista-redes.rediris.es

permanente de información técnica y comercial, de acuerdo a la experiencia de CALS International. .

\begin{tabular}{|c|c|c|c|c|c|c|c|}
\hline Origen/ Actor & $\begin{array}{c}\text { UNECE/ } \\
\text { CEFACT }\end{array}$ & ISO & IEC & ITU & OASIS & $\begin{array}{c}\text { CALS } \\
\text { INTERNATI ONAL }\end{array}$ & $\begin{array}{c}\text { NATO } \\
\text { CALS }\end{array}$ \\
\hline Origen público & $\mathbf{X}$ & & & & & & $\mathbf{X}$ \\
\hline $\begin{array}{c}\text { Origen mixto } \\
\text { (gubernamental con } \\
\text { participación } \\
\text { privada) }\end{array}$ & & $\mathbf{X}$ & $\mathbf{X}$ & & & & \\
\hline $\begin{array}{c}\text { Origen mixto } \\
\text { (privado con } \\
\text { participación } \\
\text { gubernamental) }\end{array}$ & & & & & $\mathbf{X}$ & $\mathbf{X}$ & \\
\hline Origen privado & & & & & \\
\hline
\end{tabular}

Tabla 2. Clasificación de actores internacionales, según su origen.

De acuerdo con los datos de la Tabla 2, de los siete actores internacionales que están involucrados en la creación de los estándares internacionales para el comercio electrónico a escala global, sólo dos de ellos son de origen público: el UNECE/CEFACT el cual forma parte de la ONU y NATO CALS Organisation que se encuentra en el marco de cooperación de la OTAN (NATO, por sus siglas en inglés). Tres de ellos son mixtos: ISO, IEC e ITU, es decir, que están integrados por gobiernos y empresas y/o asociaciones privadas $\mathrm{y}$, finalmente, tenemos dos actores internacionales más que son netamente privados: OASIS y CALS International.

Al analizar la morfología de esta red política que se genera para desarrollar y fijar los estándares internacionales del comercio electrónico, es posible observar la emergencia de nuevas estructuras de poder en la sociedad mundial del siglo XXI, en las que interactúan de manera coordinada tanto el sector público como el sector privado.

Consideramos que la formación de esta red política es reflejo del cambio socioinstitucional que presenta el nuevo paradigma tecno-económico caracterizado por una estructura multipolar en la que los vínculos de cooperación entre los organismos internacionales y las empresas trasnacionales forman esferas de autoridad (Rosenau, 2002) desde donde se diseñan las normas técnicas, las políticas y/o recomendaciones sobre el comercio electrónico a escala mundial. 
REDES- Revista hispana para el análisis de redes sociales

Vol.17,\#5, Diciembre 2009

http: // revista-redes.rediris.es

En la red de cooperación política que analizamos en este artículo, las interacciones entre los actores internacionales se establecen para intercambiar recursos de poder y conformarse como una esfera de autoridad legítima. Estos recursos de poder están relacionados con el conocimiento técnico, la autoridad para diseñar políticas y emitir recomendaciones a los gobiernos y empresas, la información que poseen así como la capacidad de convocatoria y legitimidad que tienen para lograr consensos y alcanzar acuerdos entre las partes involucradas, que permitan establecer los cierres tecnológicos necesarios para que las operaciones comerciales en el ciberespacio puedan realizarse y convertirse en una práctica social característica del nuevo paradigma tecno-económico del siglo XXI (Ilustración 2).

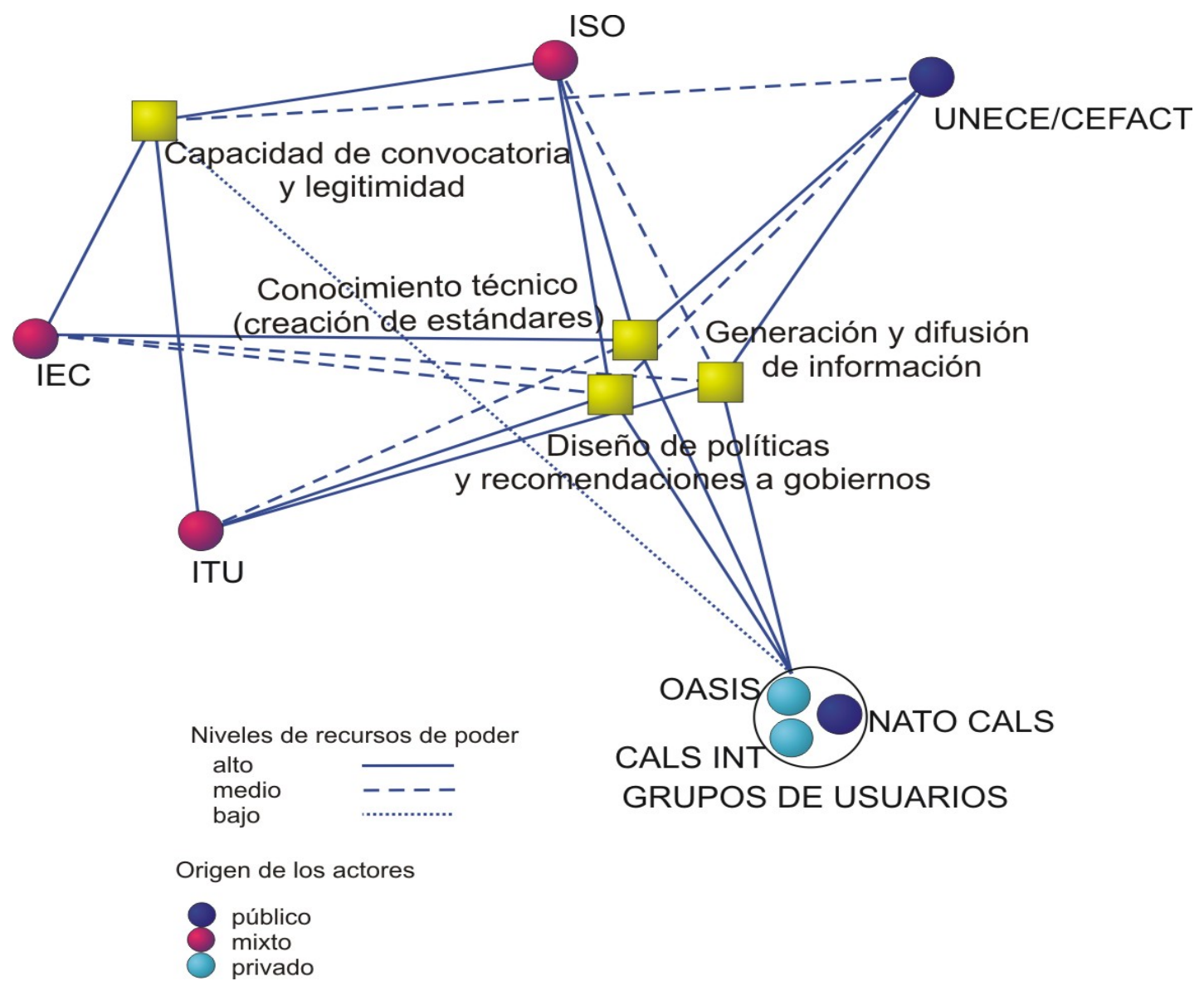


REDES- Revista hispana para el análisis de redes sociales

Vol.17,\#5, Diciembre 2009

http://revista-redes.rediris.es

I lustración 2. Red de cooperación política.

Según apreciamos en la Ilustración 2, el principal recurso de poder con el que cuenta UNECE/CEFACT es su experiencia en el diseño de estándares para el comercio electrónico, debido a su experiencia previa en el desarrollo de los estándares $\mathrm{EDI}^{24}$. Desde los años 60 pero sobre todo en la década de los 70 , con la creciente segmentación de la producción en distintos mercados y la expansión de las inversiones extranjeras, este Centro (que anteriormente se llamaba EDIFACT) se encargó de desarrollar los estándares EDI (Exchange Data Information) para el intercambio de información comercial a través de medios electrónicos, con lo cual se agilizaron las operaciones del comercio mundial, sobre todo del comercio intrafirmas en Europa, Japón y los Estados Unidos. Sin embargo, debido a que la programación de las aplicaciones de comercio electrónico utilizando los estándares EDI es muy laboriosa, ahora se ha buscando la creación de un lenguaje de programación cuyo uso sea más accesible para todas las empresas y que además, permita la clasificación de la información, es decir, la estructuración de la información en el ciberespacio.

A pesar de algunas reticencias al interior del Centro por parte de los ingenieros que en él colaboran y que se consideran los expertos en los estándares EDI, el CEFACT se ha dado a la tarea de desarrollar un lenguaje más adecuado y sencillo para realizar operaciones comerciales en Internet, utilizando $\mathrm{XML}$, según comentamos con anterioridad. Es por ello, que UNECE/CEFACT colabora estrechamente con OASIS, organización que se ha especializado en el desarrollo del $\mathrm{XML}^{25}$ para asegurar la interoperabilidad de los negocios electrónicos. Por lo que las Naciones Unidas, a través de UNECE/CEFACT está colaborando con OASIS que representa a este grupo de ingenieros de todo el mundo que, bajo el lema de trabajar con una ética informática basada en la construcción de sistemas con código estandarizado y

\footnotetext{
${ }^{24}$ Recordemos que el UNECE/CEFACT se crea a partir del grupo de tecnólogos que al interior de la UNECE se encargaron de desarrollar estándares para el intercambio de información comercial entre las empresas (EDI), prácticamente desde el inicio del proceso de integración europea.

${ }^{25} \mathrm{El}$ desarrollo de Internet como un espacio económico global, requiere que las redes que integran el ciberespacio sean interoperables para intercambiar la información comercial y sobre todo, de reusar la información comercial. Existen lenguajes de codificación que, al trabajar por etiquetas, permiten la clasificación y reuso de la información. Tal es el caso del XML. El XML es un leguaje que se está utilizando para intercambiar información de diversa índole. Se ha considerado a este lenguaje sumamente adecuado para las transacciones comerciales porque al permitir el reuso de la información, se agiliza el envío y recepción de información entre las partes involucradas en una operación comercial. Es por ello que OASIS se encuentra desarrollando estándares para el comercio electrónico basados en el lenguaje de marcado XML. La programación bajo los estándares EDI es más complicada y laboriosa que los estándares para el comercio electrónico que OASIS y la ONU (a través del UNECE/CEFACT), están desarrollando.
} 
REDES- Revista hispana para el análisis de redes sociales

Vol.17,\#5, Diciembre 2009

http: // revista-redes.rediris.es

público, ha ofrecido el desarrollo de sus innovaciones al proyecto de Naciones Unidas relacionado con la operación del ciberespacio.

OASIS representa el tipo de ingenieros con los que el UNECE/CEFACT quiere colaborar. Este grupo de tecnólogos se ha comprometido desde la constitución de OASIS, a no hacer registros de propiedad intelectual sobre los estándares técnicos que se desarrollan en el marco de esta organización. Mientras que otras organizaciones de estándares para Internet como el W3C no se comprometen a establecer una política de propiedad intelectual de este tipo, es decir, en el que se le reconozca a OASIS su autoría renunciando a cualquier derecho comercial sobre las innovaciones realizadas.

En realidad, es su alianza con OASIS lo que le otorga a UNECE/CEFACT su fortaleza. El conocimiento especializado que los miembros de este Centro han desarrollado para la elaboración de documentos comerciales digitales, le confiere al UNECE/CEFACT una fortaleza que otros de los actores internacionales no tienen para diseñar los estándares bajo los cuales deben configurarse los documentos comerciales. Su alianza con OASIS es lo que ha permitido a este Centro lazar iniciativas novedosas basadas en el lenguaje XML, como es el caso del UBL. La importancia de OASIS en esta red política radica en su alta especialización en la elaboración de estándares de comercio electrónico basados en XML, recurso de poder que quedó confirmado al momento de considerar a OASIS como participante en la segunda versión del Memorando de Entendimiento de 1998, al que ya nos hemos referido con anterioridad.

Mediante este Memorando UNECE, a través de CEFACT inicia formalmente un compromiso de diálogo y cooperación no sólo con OASIS sino también con otras organizaciones desarrolladoras de estándares para el funcionamiento de Internet como un espacio económico global. En la llustración 2 se aprecia que UNECE/CEFACT no tiene mucha participación en el diseño de políticas y recomendaciones, por lo que su capacidad de convocatoria y legitimidad es de nivel medio ya que no es reconocido hasta el momento, como la organización encargada de establecer por sí sola los estándares del comercio en Internet. Además, al ser un centro especializado que trabaja al interior de la UNECE y que carece de personalidad jurídica propia, y por tanto de autonomía, su poder de convocatoria no es alto, mientras que otras organizaciones del propio sistema de Naciones Unidas sí lo tienen. Tal es el caso de la ITU y la ISO. 
REDES- Revista hispana para el análisis de redes sociales

Vol.17,\#5, Diciembre 2009

http: // revista-redes.rediris.es

Otra de las organizaciones internacionales que está directamente vinculada con la creación de estándares para los negocios en el ciberespacio y que suscribió junto con UNECE e ISO la primera versión del Memorando de Entendimiento de 1995, fue la IEC, quien colabora estrechamente con la OMC y con la ISO, y a quien se le reconoce en el citado Memorando como la autoridad mundial para el desarrollo y publicación de los estándares internacionales en el campo tecno-electrónico.

Según se desprende de la Ilustración 2, el principal recurso de poder de la IEC es su experiencia en el diseño y aprobación de estándares internacionales relacionados con la electricidad y la electrónica. Además, también es una organización empresarial muy antigua ya que está formada por las compañías pioneras del sector TICs. Cabe resaltar que la aceptación de los estándares internacionales es una decisión que se toma por consenso entre las empresas y asociaciones de los 60 países miembros de esta organización. La participación de la IEC en el primer Memorando de Entendimiento se debe al reconocimiento que hace la ONU, a través de ISO y UNECE a esta organización, fuertemente vinculada con la OMC. La legitimidad de esta organización internacional está fundamentada en su conocimiento y expertisse que ha desarrollado para la creación de estándares internacionales desde el inicio de las innovaciones en el sector TICs. Sin duda, su legitimidad se fortalece al momento en que la OMC respalda sus decisiones.

Finalmente, el tercer actor internacional que firmó el Memorando de Entendimiento de 1995 fue la ISO. En la Ilustración 2 podemos observar que el principal recurso de poder de esta organización internacional es su capacidad para generar y difundir las normas técnicas relacionadas con los estándares en el comercio electrónico. La difusión hacia todos los países y empresas del mundo la hace mediante la aprobación y publicación de las normas ISO consensuadas por los organismos de normalización de cada país. Sus estándares son respaldados por la ONU ya que es su órgano consultivo en la materia. Esto permite a la ISO tener también poder de convocatoria y legitimidad muy alto, ya que los gobiernos de los países miembros de la ONU acatan sus resoluciones y adoptan sus estándares al armonizar sus normas oficiales con las internacionales aprobadas en el marco de la ISO.

Después de que en 1995 la UNECE, ISO y IEC firmaron el primer Memorando de Entendimiento relativo a la estandarización en el ámbito de los negocios electrónicos, en 1998 se incorpora la ITU como organización signataria y se reconoce al grupo de usuarios como participantes de este mecanismo un 
REDES- Revista hispana para el análisis de redes sociales

Vol.17,\#5, Diciembre 2009

http: // revista-redes.rediris.es

compromiso de colaboración estrecha entre las siente organizaciones a fin de evitar duplicación de tareas y posibles choques.

El papel de ITU es importante en esta red política porque es en esta organización en la que los intereses de las empresas de telecomunicaciones - principalmente estadounidenses- están representados. Según señalamos en páginas anteriores, esta organización emite, en coordinación con dichas empresas, asociaciones del sector y centros de investigación, recomendaciones técnicas y políticas, sobre el sector de las telecomunicaciones. Las recomendaciones están dirigidas a los gobiernos reconocidos por la ONU, quienes adoptan dichas recomendaciones. Además de ser parte del sistema de Naciones Unidas, la antigüedad de la ITU, le confiere un tipo de legitimidad fundada no sólo en la tradición, sino también en el conocimiento e información que genera en relación con las telecomunicaciones en el mundo y la adopción de sus recomendaciones por parte de los países miembros de la ONU.

La participación de la ITU era importante en esta red política porque a través de ella, las empresas y países miembros de esta organización se comprometen a respetar los estándares internacionales que sobre la materia emita la ISO. De ahí que la posición de ISO en la Ilustración 2, esté al centro de la red y muy cercana a la ITU, ya que son estas dos organizaciones las que se encargan de emitir las normas, directivas y recomendaciones a todos los gobiernos del mundo, ejerciendo una gran influencia sobre ellos para comprometerlos a adoptar los estándares internacionales ISO. Con el Memorando de Entendimiento ISO y la ITU legitiman los trabajos que realiza la UNECE a través del CEFACT y en colaboración estrecha con otras organizaciones de estándares para Internet así como con el grupo de usuarios representado por las empresas civiles, militares y la comunidad de ingenieros de todo el mundo reunidos en OASIS.

En esta red política observamos que las fuentes de legitimidad son el conocimiento, la generación y difusión de información especializada, la capacidad de convocatoria y el diseño de políticas y recomendaciones a los gobiernos, recursos de poder que los actores internacionales estudiados no poseen todos por igual ya que su especialización les confiere en mayor medida sólo algunos de estos recursos. Además, su alta especialización y heterogeneidad los obliga a cooperar con otros actores internacionales para establecer las normas técnicas del comercio en Internet. El Memorando de Entendimiento para la estandarización en el área de los 
REDES- Revista hispana para el análisis de redes sociales

Vol.17,\#5, Diciembre 2009

http: // revista-redes.rediris.es

negocios electrónicos sin duda representa un compromiso que favorece la cooperación internacional entre los actores firmantes para evitar la Torre de Babel en el ciberespacio ${ }^{26}$.

Las relaciones de cooperación que se establecen en esta red política son para coordinar mejor las acciones y evitar por un lado, la duplicación de tareas y, por otro, los conflictos entre las mismas organizaciones internacionales involucradas en la elaboración de estándares para los negocios electrónicos. Pero la cooperación no implica que el conflicto no esté presente en esta red, ya que toda red social presenta formas de cooperación y de conflicto.

Sin embargo, para este trabajo hemos considerado sólo las acciones de cooperación para identificar los mecanismos de gobernanza ${ }^{27}$, mediante los cuales se establecen los compromisos mínimos de colaboración entre las partes firmantes. Siendo estos mecanismos de gobernanza el Memorando de Entendimiento, las normas técnicas, esto es, los estándares ISO; los grupos de trabajo que establecen las organizaciones entre ellas, como es el caso de la ISO con la IEC, de cuya colaboración han surgido los estándares ISO-IEC 20000 que consisten en una serie de normas y especificaciones técnicas para los Servicios de Administración (Service Management) que se proporcionen en el ciberespacio.

Otro de los mecanismos de gobernanza que se estableció fue el grupo de trabajo entre la ISO y la IEC, el ISO/IEC/JTCI encargado de mantener la comunicación entre ambas organizaciones a fin de reconocerse mutuamente, acelerando las acciones para que todos los países adopten los estándares que reconozcan dichas organizaciones internacionales. De igual manera, el Centro que la ISO y la IEC han desarrollado para difundir estos estándares y brindar asesoría técnica para la adopción de los mismos.

\footnotetext{
${ }^{26}$ Marquina, M.L. (2006: 314 )

27 Para una mejor comprensión sobre los mecanismos de gobernanza del comercio en Internet, consultar Marquina, M. L. (2007).
} 
REDES- Revista hispana para el análisis de redes sociales

Vol.17,\#5, Diciembre 2009

http: // revista-redes.rediris.es

Por otra parte, la creación de un lenguaje universal para los negocios electrónicos busca también ser un mecanismo de gobernanza, porque es una forma de dar a la información un ordenamiento, una estructuración en un contexto globalizado.

Estos mecanismos de gobernanza que se establecen para darle un ordenamiento técnico al ciberespacio son instrumentos de soft law ya que representan acuerdos que no se negocian por los gobiernos de los Estados sino por las organizaciones internacionales reconocidas por éstos y en las que las empresas trasnacionales están presentes y juegan un papel fundamental en tanto que poseen el conocimiento técnico necesario para diseñar los estándares internacionales. Estos mecanismos de gobernanza son instrumentos de soft law por que corresponden a un tipo de ordenación social más flexible y menos coercitiva que el derecho internacional. Son este tipo de mecanismos de gobernanza los que han establecido los actores internacionales miembros de esta red política, cuyos miembros se reconocen mutuamente como las autoridades legítimas para el establecimiento de los estándares internacionales para los negocios electrónicos.

Con la creación de los estándares técnicos ISO 15000 y la firma del Memorando de Entendimiento, el sistema de las Naciones Unidas, a través de UNECE/CEFACT, la ISO, la ITU y la IEC establecen un cierre tecnológico que favorece la facilitación del comercio internacional y con ello, el proceso de globalización de la economía mundial, ya que mediante la creación y utilización de estos estándares, las empresas de cualquier tamaño pueden encontrar a sus socios potenciales en el ciberespacio, evitándoles de este modo, una posición marginal en el mismo.

\section{Conclusiones}

El cambio de paradigma tecno-económico suscitado por las tecnologías de información y comunicación ha generado transformaciones en la estructura de la sociedad mundial, tanto en lo tecnológico y económico como en lo político. La convergencia creciente entre las tecnologías de información y comunicación ha hecho posible desarrollar una red global de información a la que denominamos Internet y mediante la cual se pueden agilizar las transacciones comerciales de diversa índole y acortar los ciclos de retorno del capital. 
REDES- Revista hispana para el análisis de redes sociales

Vol.17,\#5, Diciembre 2009

http: // revista-redes.rediris.es

Según presentamos en este artículo, la definición de Internet como un espacio económico global fue posible a partir de dos situaciones: por el lado técnico, hasta que se desarrollaron los protocolos de Internet $y$, por el lado político, el término del conflicto Este-Oeste que provocó la expansión del capitalismo a nivel mundial. Sin embargo, no todo ha quedado resuelto. Al contrario. El uso comercial de Internet a escala global plantea nuevas problemáticas no sólo de carácter técnico sino también político, económico, jurídico y social, en las que se involucran ciertos actores internacionales para su solución.

La posibilidad de que Internet sea un espacio económico global se fundamenta en el principio de interoperabilidad entre las redes. El riesgo de una Torre de Babel en el ciberespacio en donde exista mucha información pero que no pueda fluir libremente o que no se encuentre clasificada y pueda reutilizarse, limita el potencial de la autopista de la información. Para que realmente Internet contribuya a la facilitación del comercio mundial y por ende, a la reducción de costos, es indispensable que los agentes económicos y gubernamentales puedan estar en permanente interacción y comunicación a través de sus sistemas de información. Según el modelo de organización propuesto por CALS International esto es posible y ha quedado reflejado en el nuevo rubro de las normas ISO 20000.

Pero el flujo continuo de información sólo es posible si existe interoperabilidad entre las máquinas y los códigos. Por ello, las Naciones Unidas a través de UNECE/CEFACT, ha logrado establecer un compromiso de colaboración con los organismos técnicos internacionales como ISO, IEC e ITU para generar los estándares necesarios que permitan la interoperabilidad de las transacciones electrónicas en el ciberespacio. Además de ello, ha lanzado una iniciativa que permita la creación de un lenguaje universal para los negocios electrónicos. Dicho código informático asegura al menos técnicamente, que todas las empresas puedan participar en los mercados electrónicos globales y realizar en el espacio virtual un sinnúmero de transacciones.

Para avanzar en este sentido e impulsar la creación de Internet como un espacio económico global, las Naciones Unidas a través de UNECE/CEFACT ha promovido la creación de espacios de diálogo permanente y de cooperación entre las organizaciones internacionales involucradas en la conformación del ciberespacio. De esta forma, se han establecido estrechas relaciones de colaboración entre ellas. Su alta especialización las hace más interdependientes unas de las otras y esta división 
REDES- Revista hispana para el análisis de redes sociales

Vol.17,\#5, Diciembre 2009

http: // revista-redes.rediris.es

del trabajo social las obliga a cooperar para lograr la meta común con la que están comprometidas en el marco de la reproducción del sistema capitalista a nivel mundial. De ahí la integración de la red política que se establece entre UNECE/CEFACT, ISO, IEC, ITU y los grupos de usuarios del comercio en Internet.

La conformación de esta red política que se compromete a cooperar, a no duplicar tareas y a apoyarse mutuamente quedó establecida a partir de la firma del Memorando de Entendimiento para la estandarización en el área de los negocios digitales. Este instrumento que actúa como un mecanismo de gobernanza para el ordenamiento del ciberespacio, confirma el compromiso de colaboración entre los actores internacionales públicos, privados y mixtos.

Lo novedoso de la integración de este tipo de redes en el sistema internacional es que a través del establecimiento de relaciones formales de cooperación política entre los actores internacionales, como los Memoranda de Entendimiento, las iniciativas conjuntas como el UBL, o la creación de grupos de trabajo. A través de estos mecanismos de gobernanza se intercambian los recursos de poder necesarios para complementarse mutuamente y erigirse como una esfera de autoridad legítima para emitir las normas técnicas y las políticas de armonización relacionadas con los negocios en el ciberespacio.

La conformación de este tipo de redes políticas es reflejo del cambio de paradigma tecno-económico caracterizado por la convergencia tecnológica de las TICs y el proceso de globalización de la economía mundial, transformaciones que van acompañadas de un cambio en las estructuras político-institucionales. El nuevo contexto socio-institucional del nuevo paradigma tecno-económico está caracterizado por la descentralización del poder político y por la formación de redes políticas en las que participan no sólo los Estados nación sino también las empresas trasnacionales y sus asociaciones a nivel mundial y, en mucha menor medida, las organizaciones de ciudadanos. En este modelo de organización socio-política la autoridad no está concentrada en un solo actor por lo que su legitimidad no está basada en la coerción sino en una autoridad compartida con otros a través del consenso y el conocimiento especializado. Por lo que estos dos elementos son el fundamento de las nuevas esferas de autoridad que se conformar a partir del establecimiento de redes políticas que diseñan políticas trasnacionales para afrontar los problemas globales del nuevo paradigma tecno-económico de la sociedad mundial. 
REDES- Revista hispana para el análisis de redes sociales

Vol.17,\#5, Diciembre 2009

http: // revista-redes.rediris.es

\section{Bibliografía}

Arroyo, G. (1999). Metodología de las Relaciones Internacionales, México, Oxford University Press.

Casas, R. (2003). “Enfoque para el análisis de redes sociales y flujos de conocimiento" en Luna, M. (coord.), Itinerarios del conocimiento: formas dinámicas y contenido. Un enfoque de redes, México, Anthropos-UNAM, pp. 19-50.

CEPAL (2005). “La facilitación del comercio y la integración Centroamericana: modernización de aduanas", Boletín Facilitación del Comercio y el Transporte en América Latina, no. 222, pp. 1-4.

Gerstein, M. (1988). Encuentro con la tecnología. Estrategias y cambios en la era de la información, México, Addison-Wesley I beroamericana.

Gilpin, R. (2002). "A Realist Perspective on International Governance" en Held, D. y A. McGrew (coords.), Governing Globalization. Power, Authority and Global Governance, U.K, Polity Press. pp. 237-248.

I báñez, J. (2002). Poder y Autoridad en las Relaciones Internacionales, Barcelona, Universidad Pompeu Fabra.

Marquina, M.L. (2006). "Redes de Gobernanza Global y Comercio en Internet" en Graciela Arroyo (coord.), La dinámica mundial del siglo XXI. Revoluciones, procesos, agentes y transformaciones, México Cenzontle, 2006 pp. 307-322.

Marquina, M.L. (2007). Gobernanza global del comercio en Internet, Tesis doctoral, México, UNAM.

Messner, D. (1999). “Del Estado céntrico a la sociedad de redes. Nuevas exigencias a la coordinación social" en Norbert Lechner et al., Reforma del Estado y coordinación social, México. Plaza y Valdés-IIS, UNAM, pp. 77-121.

Molina, J.L. (2001). El análisis de redes sociales. Una introducción, España, Ediciones Bellaterra.

Pérez, C. (2003). “Revoluciones tecnológicas, cambios de paradigma y de marco socio-institucional", en Aboites, J. y G. Dutrénit (coords.), Innovación, aprendizaje 
REDES- Revista hispana para el análisis de redes sociales

Vol.17,\#5, Diciembre 2009

http://revista-redes.rediris.es

y creación de capacidades tecnológicas, México, UAM-Miguel Angel Porrúa, pp. 1346.

Rosenau, J. (2002). "Governance in a New Global Order", en Held, D. y A. McGrew (coords.), Governing Globalization. Power, Authority and Global Governance, U.K, Polity Press. pp. 70-87.

Strange, S. (1996). The Retreat of the State. The Diffusion of Power in the World Economy, U.K.: Cambridge University Press. 